\title{
[DITORIA \\ Education and Training: Integrating the Disaster Cycle
}

\author{
James J. James, MD, DrPH, MHA
}

$\mathrm{I}$ n my April 2014 editorial, a discussion of the education and training model for the discipline of emergency medicine and public health, as envisioned by the Society for Disaster Medicine and Public Health, was promised for the succeeding issue in June. For multiple reasons, this discussion was deferred. Again, this deferral has been extended because change in this area is occurring so quickly that a revision would soon be required. We sincerely hope that before the end of the year we will be able to publish the initial blueprint of our model and present it for further discussion and input.

Much of the education and training model is being driven by the increasing realization that the disaster cycle must be viewed as a continuum and not as a linkage of 4 semidiscrete functions: response, recovery, mitigation/prevention, and planning. When seen as part of a linkage, each function is considered the providence of separate disciplines that seemingly hand off the baton to a different set of players, and a different phase is entered. It is true, however, that in different parts of the cycle, the relative impacts will vary across scenarios, most notably for a biological event versus other natural events.

In the current issue of the journal, the importance of these considerations are highlighted. The proceedings of the preparatory meeting for the upcoming Hyogo Framework conference(s) in Japan, with additional commentaries from Drs Burkle and Egawa, carry several important messages. ${ }^{1,2}$ Two of these will propel development of our society: (1) health must be recognized as a critical element for disaster risk reduction and improved population resiliency, and (2) although the medical and health role in response is essential, even greater health benefits might accrue through larger investments in recovery, preparation, and planning. As Burkle et al have noted, for every US dollar spent on risk reduction, $\$ 4$ of emergency response is saved. ${ }^{3}$

Additional work from the Rockefeller Foundation has shown that building resilience lowers the costs of response and recovery. ${ }^{4} \mathrm{~A}$ note of caution on these issues, however, is included in Egawa's summary ${ }^{5}$ : "a disaster is always measured by the death toll, number of injured, and the loss of property." I would add that the health system will always be measured by the efficiency and effectiveness of its response. Care must be taken that we do not allow the pendulum to swing too far to the importance of response in the disaster cycle. Understanding the importance of all of the components is needed to achieve a better balance. This point is well demonstrated by Rath's contribution to this issue's On the Cover (pp?), which highlights an effective, systematic response to a tornado event by a small hospital system. The response was effective because response personnel were educated and trained, a plan was in place, and that plan had been practiced.

As we proceed in developing the society and the discipline of disaster medicine and public health, we are committed to an education and training model that supports curricula based on a set of commonly accepted core competencies across all health disciplines that allows for reliable assessment of capable providers as part of an overall system. Further, that education and training must address health and medical requirements and inputs for all components of the disaster cycle for all major scenarios. This process, of course, is an evolutionary one, but it has begun-the goal is an improved level of global health security.

\section{REFERENCES}

1. Burkle FM Jr. Hyogo Declaration and the cultural map of the world [editorial]. Disaster Med Public Health Prep. 2014; 8(4): 280-282.

2. Egawa S, MacIntyre AG, Beadling CW, Walsh JT, Shimomura O. International Symposium on Disaster Medicine and Public Health Management: Review of Hyogo Framework for Action. Disaster Med Public Health Prep. 2014; 8(4):357-358.

3. Burkle FM Jr, Martone G, Greenough PG. The changing face of humanitarian crises. Brown J World Affairs. 2014; 20(11):25-42.

4. Rodin J. Announcing the Global Resilience Partnership [blog]. New York, NY: The Rockefeller Foundation website; 2014. http://www.rockefellerfoundation.org/blog/announcing-globalresilience. Accessed August 21, 2014. 